\title{
Testing Dynamic Models of Worker Effort
}

\author{
Stephen Machin, University College London
}

Alan Manning, London School of Economics

This article derives three dynamic models of worker effort determination, based on a shirking efficiency wage model, a compensating differentials model, and a union-firm bargaining model. It shows that all of these three models have the same long-run comparative statics but differ in their short-run dynamics. We use these different predictions about the dynamics as a basis for testing the models. Euler equations for each model are estimated using panel data on 486 U.K. companies. The evidence supports the shirking model in firms with low levels of unionization but the bargaining model in highly unionized industries.

\section{Introduction}

Efficiency wage theories have, in recent years, deservedly attracted a lot of attention as a potential explanation of involuntary unemployment and other aspects of the labor market. However, virtually all the research in efficiency wage theory has been theoretical, and testing the theory has proved remarkably difficult.

One empirical approach (e.g., Krueger and Summers 1988) is to argue that observed interindustry wage differentials are not consistent with com-

We would like to thank seminar participants at Trinity College, Dublin, the Universities of Manchester, Marseille, Warwick, and Bristol, the Institute for International Economic Studies at the University of Stockholm, and Employment Market Research Unit (EMRU) for their helpful comments. Thanks also go to Xeni Dassiou and John van Reenen for help with setting up the data. Alan Manning would like to thank the Leverhulme Trust for financial support.

[Journal of Labor Economics, 1992, vol. 10, no. 3]

(C) 1992 by The University of Chicago. All rights reserved.

0734-306X/92/1003-0005\$01.50 
petitive theory but are consistent with some version of efficiency wage theory. However, this evidence is not uncontroversial (e.g., see Murphy and Topel 1987; Gibbons and Katz 1989) and is at best indirect as efficiency wage models are not the only alternatives to competitive theories. Given this, the more direct approach of Wadhwani and Wall (in press) and the "cost-of-job-loss" literature (see, e.g., Weisskopf, Bowles, and Gordon 1983 ) is refreshing. They argue that the popular shirking version of efficiency wage theory (Shapiro and Stiglitz 1984) predicts that worker productivity is higher the higher are wages in a given firm relative to the utility that workers could get elsewhere. They estimate production functions and find evidence in line with this view. However, as Wadhwani and Wall acknowledge, this finding remains consistent with notions of compensating differentials and with bargaining theory, so the results cannot be interpreted as strongly in favor of efficiency wage theory.

The purpose of this article is to shed further light on these issues. We present dynamic versions of Shapiro and Stiglitz's (1984) shirking model, of a compensating differentials model, and of a bargaining model. We confirm that, in the long run, all models predict that worker effort in a firm will be related to the difference between wages and utility available on the more general labor market. However, the dynamics of effort determination are different in the three models. The basis for our test is that, in shirking efficiency wage models, worker effort should be positively related not just to current wages but also to future expected wages, because if wages are going to be high in the future, the cost of losing a job today will be high. As we shall see, the other models do not necessarily have this prediction. This means that if we estimate Euler equations for worker effort we might hope to provide a more discriminating test of efficiency wage theory than has been done before. This is the main advantage of our approach.

However, our approach does have its disadvantages. First, it concentrates on a particular version of efficiency wage theory, namely, the shirking model. Also, the approach puts considerable weight on some dynamic assumptions that may be quite strong. For example, our approach could not really be expected to be a test of the more "sociological" versions of efficiency wage theory (e.g., Akerlof 1982), as it is not clear what a dynamic version of such a model would look like. In addition, our Euler equations are based on Markov perfect equilibria and may not capture the repeated game aspects of efficiency wage models that have been emphasized by Macleod and Malcomson (1989). ${ }^{1}$ For these reasons, we prefer to think

${ }^{1}$ It would be nice to present a test of the efficiency wage models of Macleod and Malcomson (1989), which look at all perfect equilibria rather than only Markov perfect equilibria. However, this is likely to be difficult as, in common with many repeated-game situations, there are an infinite number of possible perfect equilibria, making the chance of deriving strong empirical predictions rather small. 
of the tests presented here as supplementary evidence on the plausibility and importance of efficiency wage theory.

The plan of this article is as follows. In the next section, we present our basic theoretical models: a dynamic shirking model, a compensating differentials model, and a dynamic bargaining model. In the third section, we discuss how we can base empirical tests on these models. In the fourth section, we implement these tests on a panel of British companies. The results for the overall sample are not consistent with the efficiency wage model and appear to be more in line with the bargaining model than with the compensating differentials model. But, when we split the sample of firms into low and high union industries, the efficiency wage model seems to perform best for the low union sector and the bargaining model seems to perform best in the high union sector.

\section{The Theoretical Model}

In this section, we present dynamic versions of a Shapiro-Stiglitz model, a compensating differentials (competitive) model, and a bargaining model.

The setup common to all three is the following. Assume that workers in a firm at date $t$ get current utility $U\left(W_{t}, e_{t}\right)$, where $W_{t}$ is the real wage and $e_{t}$ is effort. We assume that $U_{W}>0, U_{c}<0$. In the empirical section below, to help with the derivation of estimable equations, it will be convenient to assume that $U\left(W_{t}, e_{t}\right)=w_{t}-e_{t}$, where lowercase letters denote logarithms. Most of the existing literature makes this assumption that $U_{W_{e}}$ $=0$, and, as we shall see in the theoretical section, it does make the comparative statics of the model more clear-cut than they would be otherwise.

We assume that there is a probability $q$ that the worker will leave the firm before next year. Then, if we denote the value of a job in this firm in year $t$ by $V_{t}$ and the value of being on the open labor market by $\bar{V}_{t}$, we will have

$$
V_{t}=U\left(W_{t}, e_{t}\right)+\delta\left[(1-q) E_{t} V_{t+1}+q E_{t} \bar{V}_{t+1}\right],
$$

where $\delta$ is the discount factor and $q$ is the labor turnover rate (which we treat as exogenous). If a worker is on the open labor market, we will assume that his or her current expected utility is $\bar{u}_{t}$, which will be determined by wages in other firms, the level of unemployment benefit, and the chance of employment. If we assume that the firm under consideration is small in relation to the rest of the economy, so that a worker never expects to return to the same firm once he or she has left it, we will have ${ }^{2}$

${ }^{2}$ One might also want to distinguish two alternative states: employment elsewhere and unemployment. Doing this does not alter the basic prediction of the shirking model that effort should be positively correlated with future wages, but it does introduce an extra set of lags into the estimable Euler equations that are difficult to pick up in the estimation. 


$$
\bar{V}_{t}=\bar{u}_{t}+\delta E_{t} \bar{V}_{t+1} .
$$

Using (2), we can write (1) as

$$
\left(V_{t}-\bar{V}_{t}\right)=U\left(W_{t}, e_{t}\right)-\bar{u}_{t}+\delta(1-q) E_{t}\left(V_{t+1}-\bar{V}_{t+1}\right) .
$$

In what follows, we look at Markov perfect equilibria in which the employer cannot commit future wages in advance. So, $V_{t+1}$ will be regarded as independent of any decisions taken at time $t$. This assumption is probably reasonable given that we will be working with annual data and wage contracts that are generally 1 year in length in the United Kingdom.

Now consider how we can use these models to analyze the implications of three different labor market models.

\section{A. A Dynamic Shirking Model}

Consider the following simple dynamic version of the Shapiro-Stiglitz (1984) model. We assume that workers who do not shirk have a value function $V_{t}$, which is given by (1). If workers do shirk, they put in some minimum effort level that we normalize so that $e_{t}=0 .{ }^{3}$ In this case, there is a probability $p$ that they are not caught, in which case their utility is $\left[V_{t}-U\left(W_{t}, e_{t}\right)+U\left(W_{t}, 0\right)\right]$ and a probability $(1-p)$ that they are caught. In this case, we assume that the worker receives expected utility $\theta U\left(W_{t}, 0\right)+\phi \bar{u}_{t}$ this period and is then fired. Shapiro and Stiglitz assumed that $\theta=1, \phi=0$, which corresponds to the case where shirking workers get paid for the whole period and are fired at the end of the period. However, in a more realistic model, there is some chance that workers get fired in the middle of the year, and it is natural to assume that $\theta<1, \phi>0$. In addition, if there is some monetary "punishment" of shirking workers, we may have $(\theta+\phi)<1$. be

Combining this information, the valuation function for a shirker will

$$
\begin{aligned}
V_{t}^{S}= & p\left[V_{t}-U\left(W_{t}, e_{t}\right)+U\left(W_{t}, 0\right)\right] \\
& +(1-p)\left[\theta U\left(W_{t}, 0\right)+\phi \bar{u}_{t}+\delta E_{t} \bar{V}_{t+1}\right]
\end{aligned}
$$

If efficiency wage theory is relevant, it must be the case that $\left(W_{t}, e_{t}\right)$ are set so that $V_{t}=V_{t}^{S}$. One could interpret this in a number of ways. One could think of the firm as choosing $\left(W_{t}, e_{t}\right)$ to maximize profits subject to the constraint $V_{t} \geq V_{t}^{S}$. Or one could think of wages as being determined by some other process, for example, collective bargaining, and the firm then unilaterally setting the maximum possible effort consistent with no

${ }^{3}$ Assuming that a shirking worker puts in a nonzero effort level will simply add a constant to our equations. 
shirking. Or wages and effort could both be determined by collective bargaining, but the no-shirking condition happens to bind. For our purposes this does not matter; if efficiency wage considerations are important, we must have $V_{t}=V_{t}^{S}$. Substituting this condition into (4) and using (2) lead to

$$
\begin{aligned}
V_{t}= & \frac{p}{1-p}\left[U\left(W_{t}, 0\right)-U\left(W_{t}, e_{t}\right)\right] \\
& +\left[\theta U\left(W_{t}, 0\right)+(\phi-1) \bar{u}_{t}+\bar{V}_{t}\right] .
\end{aligned}
$$

Substituting (5) into (3) and rearranging lead to

$$
\begin{aligned}
& \frac{1}{1-p}\left[U\left(W_{t}, e_{t}\right)\right]=\phi\left(\bar{u}_{t}\right)+\delta(1-q)(1-\phi) E_{t} \bar{u}_{t+1} \\
& +\left(\frac{p}{1-p}+\theta\right)\left[U\left(W_{t}, 0\right)\right]-\delta(1-q) E_{t} \\
& \times\left\{\frac{p}{1-p}\left[U\left(W_{t+1}, 0\right)-U\left(W_{t+1}, e_{t+1}, e_{t+1}\right)\right]+\theta\left[U\left(W_{t+1}, 0\right)\right]\right\} .
\end{aligned}
$$

Equation (6) is an Euler equation for current effort in terms of future effort, current and future wages, and current and future alternative utility, which can be thought of as a dynamic no-shirking condition. We are interested in the effect of current and future wages and alternative utility levels on current effort through (6). Increases in both current and future alternative utility levels act, other things being equal, to reduce $e_{t}$. This is not surprising; as the workers' external labor market prospects improve, they must be offered a higher level of utility to stop them from shirking, and, conditional on wages, this must mean a lower effort level.

But, the effect of own wages on effort through the no-shirking condition is more subtle. First, consider the long run of (6):

$$
\begin{gathered}
U(W, e)=\frac{1}{1-p \delta(1-q)} \\
\times\{[p+\theta(1-p)][1-\delta(1-q)][U(W, 0)]+[\phi+(1-\phi) \delta(1-q)] u\} .
\end{gathered}
$$

If we simply differentiate (7), we obtain the following expression for the derivative of effort with respect to wages: 


$$
\begin{aligned}
{\left[U_{e}(W, e)\right](\partial e / \partial W) } & =\frac{1}{1-p \delta(1-q)} \\
\quad & \times[p+\theta(1-p)][1-\delta(1-q)]\left[U_{W}(W, 0)\right]
\end{aligned}
$$

$$
-U_{W}(W, e) \text {. }
$$

The standard shirking model predicts that a firm that pays higher wages can extract higher effort from its workers so that $(\partial e / \partial W) \geq 0$. Equation (8) always satisfied this under the conventional assumption that $U_{W_{e}}=0$, that is, that the marginal utility of income is independent of effort at work. In this case, paying higher wages makes not shirking more attractive relative to shirking as the worker is more likely to receive the extra wage if he or she does not shirk, and the extra wage is valued equally by shirkers and nonshirkers.

But, if $U_{W_{e}}<0$ (which corresponds to the assumption that "workers who work hard are too tired to enjoy their income"), it is possible that $(\partial e / \partial W) \leq 0$ for some values of $(W, e)$. In this case, paying higher wages raises the utility from shirking more than it raises the utility from not shirking, as shirkers have a higher marginal utility of income. Hence, paying higher wages may have the perverse effect of tightening the no-shirking condition and forcing the employer to reduce the effort required of workers.

However, we should probably not worry too much about this perverse case, as a profit-maximizing employer would always operate in a region where there is a positive trade-off between wages and effort. It is always possible to find some combination of $(W, e)$, such that this is the case, for example, for $e$ close enough to 0 (when $U_{W}(W, e$ ) will be close to $\left.U_{W}(W, 0)\right)$. So, although, in contrast to the standard shirking model, high wages need not always loosen the no-shirking condition, we would expect profit-maximizing employers to always choose a point where this is the case. Thus, as in Wadhwani and Wall (in press) and the "cost-of-job-loss" literature, we would expect long-run effort to be positively related to own wages and negatively related to alternative utility.

Now, consider using (6) to derive the short-run derivatives $\left(\partial e_{t} / \partial W_{t}\right)$ and $\left(\partial e_{t} / \partial W_{t+1}\right)$. These are given by

$$
\left[U_{e}\left(W_{t}, e_{t}\right)\right]\left(\partial e_{t} / \partial W_{t}\right)=[p+\theta(1-p)]\left[U_{W}\left(W_{t}, 0\right)\right]-U_{W}\left(W_{t}, e_{t}\right),
$$

and

$$
\begin{gathered}
{\left[U_{e}\left(W_{t}, e_{t}\right)\right]\left(\partial e_{t} / \partial W_{t+1}\right)=\delta(1-q)} \\
\times\left\{p\left[U_{W}\left(W_{t+1}, e_{t+1}\right)\right]-[p+\theta(1-p)]\left[U_{W}\left(W_{t+1}, 0\right)\right]\right\} .
\end{gathered}
$$

These derivatives are, like the long-run derivative, also ambiguous in sign. However, if $U_{W e}=0$ (or $e$ is close enough to 0 ), both $\left(\partial e_{t} / \partial W_{t}\right)$ and 
$\left(\partial e_{t} / \partial W_{t+1}\right)$ are positive. This is not surprising. Anything that makes the current job valuable can be used to induce workers to work harder, and expected future wages can fulfill this role as well as current wages. But, it is possible that, for some values of $(W, e)$, one or both derivatives are negative. However, this is most unlikely to be the case in practice. For the reasons given above, a profit-maximizing employer choosing $\left(W_{t}, e_{t}\right)$ will always end up at a point where there is a trade-off between higher wages and higher effort, that is, where $\left(\partial e_{t} / \partial W_{t}\right) \geq 0$. And if, as seems the more plausible assumption, $U_{W_{e}} \leq 0,\left(\partial e_{t} / \partial W_{t+1}\right)$ will always be positive as well. So, we take it as a prediction of the efficiency wage model that both current and future wages will, other things being equal, enable the employer to extract higher effort from the workers without inducing them to shirk.

Before proceeding to some other labor market models, let us consider whether this is an adequate representation of the shirking model. Implicit in the above formulation was the assumption that all workers in the firm put in the same effort and receive the same wage. But from Malcomson (1984) and Akerlof and Katz (1989), we know that, for example, the greater the influence of seniority on wages, the greater the effort that can be extracted from workers. So, if different firms have different returns to seniority, then the effort levels may be different even if the average level of wages is the same. If, however, returns to seniority are relatively constant over time (which seems plausible), then we can model this as a firmspecific effect, and we incorporate this into our estimation procedure.

\section{B. A Compensating Differentials Model}

Now consider what we would expect if we had a competitive market and differences in wages levels reflected different effort levels in different jobs. If we have a competitive labor market, then we will have $V_{t}=\bar{V}_{t}$ for all $t$. From (3), we then have

$$
U\left(W_{t}, e_{t}\right)=\bar{u}_{t}
$$

Notice that, just as in the shirking model, effort will, in the long run, be positively related to wages and negatively related to the alternative utility level. But the short-run dynamics of the competitive model are completely different from the shirking model (cf. [11] with [6]). In particular, the competitive model has no dynamics at all.

The compensating differentials model presented here has been very simple in assuming that jobs differ only in their wages and effort. In reality, there may be other nonpecuniary aspects of jobs, for example, working conditions that should be taken account of. In the empirical work that follows, we assume that these nonpecuniary factors do not vary over time and can be captured by firm-specific effects. 


\section{A Bargaining Model}

Now consider a third alternative in which wages and effort are determined by some sort of bargaining between employers and their workers (who may be represented by a trade union). There are many different bargaining models available, differing, for example, in whether wages, effort, or both are subject to negotiations and, if so, in what order. As our main interest is in testing efficiency wage models against alternatives, there is a danger that, if we choose a very specific bargaining model, the alternatives considered will not be general enough. So, rather than using a particular bargaining model we will use the fact that one of the predictions of all bargaining models is that $V_{t}$ will be set above $\bar{V}_{t}$. Let us capture this in a very simple way by assuming that

$$
V_{t}=\mu\left(\bar{V}_{t}\right), \mu>1 \text {, }
$$

where we assume that $\mu$ is constant. Of course, in any particular bargaining model, it is unlikely that $\mu$ will be constant. ${ }^{4}$ For example, it might depend on some exogenous variables and some future expected variables. But we are not primarily concerned with testing particular versions of bargaining models, and (12) seems to capture a feature that will be common to all of them.

Using (12) in (2), we can derive

$$
V_{t}=\mu\left(\bar{u}_{t}\right)+\delta\left(E_{t} V_{t+1}\right) .
$$

Using (13) to eliminate $E_{t} V_{t+1}$ in (1) and rearranging to obtain an expression for $V_{t}$ yields

$$
V_{t}=\frac{\mu}{q(\mu-1)}\left\{u_{t}-[(1-q) \mu+q] \bar{u}_{t}\right\}
$$

where $u_{t}=U\left(W_{t}, e_{t}\right)$. Equation (14) says, not surprisingly, that a high level of current utility is associated with a high current value of the job. Substituting (14) and the equivalent expression for $E_{t} V_{t+1}$ into equation (13) leads, after some rearrangement, to

$U\left(W_{t}, e_{t}\right)=\delta E_{t} U\left(W_{t+1}, e_{t+1}\right)+\mu\left(\bar{u}_{t}\right)-\delta[(1-q) \mu+q] E_{t} \bar{u}_{t+1}$.

${ }^{4}$ We also do not model $\mu$. The evidence reviewed in Stewart (1991) suggests that the wage markup achieved by British trade unions over this period is roughly constant, although why this should be the case in the face of the legal onslaught on unions by the government is something of a mystery that we do not resolve here. 
The long-run relationship among $e, W$, and $\bar{u}$ can be written as

$$
U(W, e)=\frac{\mu[1-\delta(1-q+q \mu)]}{1-\delta} \bar{u}
$$

so that, as in the previous theories, effort will be positively related to the wage and negatively related to the alternative utility level. However, note that the short-run dynamics of the bargaining model are very different compared with those of the shirking model (cf. [15] with [6]). In particular, in the shirking model current and future wages are predicted to have the same sign, whereas in the bargaining model they are predicted to have the opposite sign. The same is true of the alternative utility level. The intuition for this is that this result comes from the positive correlation of current and future utility that is in (15). One should probably not think that this type of dynamic structure is a general feature of bargaining models as the model presented above has very ad hoc theoretical foundations. The point we want to make is that a very rudimentary bargaining model can predict a sign on the future wage that is different from the shirking model. And one should probably not think that the negative coefficient on future wages necessarily indicates the existence of a bargaining model; some type of competitive intertemporal substitution model may also have the same prediction.

\section{From Theory to Testing}

Although the theoretical equations presented above are quite clear-cut, the main problem with empirical implementation is that two variables, the firm's effort level and the alternative utility level, are not directly observable. This section describes how we model these variables.

We follow Wadhwani and Wall (in press) in defining effort to be the residual from a production function. Approximating the production function by a Cobb-Douglas, we have

$$
y_{i t}=\alpha k_{i t}+\beta \ell_{i t}+\gamma e_{i t}+\xi_{i t}
$$

where $y_{i t}$ is $\log$ output of firm $i$ at date $t, k_{i t}$ is capital stock, $\ell_{i t}$ is employment, $e_{i t}$ is effort, and $\xi_{i t}$ is all other factors affecting the production function. What variables will affect $\xi_{i t}$ ? It will be affected by hours worked, the skill mix, the price of inputs, and technological progress. None of these variables is directly observable at firm level in our data set.

In Wadhwani and Wall (in press), hours worked and input prices are proxied by the corresponding industry-level variables. However, as we shall see, our specification of the alternative utility level should also include these variables, rendering their expected sign ambiguous. For this reason we simply model $\xi_{i t}$ as a collection of firm-specific industry and time 
dummies. The particular specification for $\xi_{i t}$ that we adopt is a very general one given by

$$
\begin{aligned}
\xi_{i t}= & a_{i}+(\text { industry dummy } \times \text { time trend }) \\
& + \text { industry dummies }+ \text { time dummies }+v_{i t},
\end{aligned}
$$

where $v_{i t}$ is some error and $a_{i}$ is a firm-specific dummy.

Putting together (16) and (17) and then rearranging leads to the following specification for effort:

$$
\begin{gathered}
e_{i t}=\frac{1}{\gamma}\left[y_{i t}-\alpha k_{i t}-\beta \ell_{i t}-a_{i}-(\text { industry dummy } \times \text { time trend })\right. \\
\left.- \text { industry dummies }- \text { time dummies }-v_{i t}\right] .
\end{gathered}
$$

It may seem very strong to assume that variations in "unexplained" output are all worker effort, but it should be remembered that the rapid rate of productivity growth in British manufacturing in the early 1980s (the middle of our sample period) is often ascribed to the elimination of restrictive practices that had previously kept worker effort low (see, e.g., Nickell, Wadhwani, and Wall 1989).

Now consider the specification of the alternative utility level, $\bar{u}_{i t}$. If a worker loses his or her job in this firm, he or she will be thrown onto the open labor market. He or she might find another job that pays a wage $\bar{w}_{i t}$ and requires effort level $\bar{e}_{i t}$, or he or she might remain unemployed, in which case he or she would receive utility level $b_{t}$, where $b_{t}$ is the level of real unemployment benefits. The probability of these two events will be related to the unemployment rate, $u r_{t}$. A reasonable specification might be

$$
\bar{u}_{i t}=u r_{t}\left(b_{t}\right)+\left(1-u r_{t}\right)\left(\bar{w}_{i t}-\bar{e}_{i t}\right) .
$$

Wadhwani and Wall effectively ignore effort in other jobs and simply measure $\bar{w}_{i t}$ by the industry wage. We also experimented with allowing the coefficient on $b_{t}$ in (19) to be $\eta\left(u r_{t}\right)$ and the coefficient on $w_{t}$ to be $\left[1-\eta\left(u r_{t}\right)\right]$, where $\eta$ is a coefficient to be estimated and is not necessarily equal to one, as assumed in (19). However, the estimated value of $\eta$ was never significantly different from unity.

We present estimates using the specification (19) below. But given that it may not be legitimate to ignore effort required in other firms and that the amount of worker movement between industries is substantial, it may be more appropriate to model the alternative utility level as simply an aggregate variable, in which case we cannot identify its effects from those of our time dummies. For this reason, we also present regressions including only industry and time dummies. 
For the purposes of empirical estimation, we assume that $U\left(W_{t}, e_{t}\right)$ $=w_{t}-e_{t}$, where $w_{t}$ is the logarithm of the wage. Then, from (6), (11), and (15), all three theories derived above imply an effort equation of the form

$$
e_{i t}=\psi_{0}+\psi_{1} E_{t} e_{i t+1}+\psi_{2} w_{i t}+\psi_{3} E_{t} w_{i t+1}+\psi_{4} \bar{u}_{i t}+\psi_{5} E_{t} \bar{u}_{i t+1},
$$

where the different theories differ in the predicted signs on the $\psi$ 's. The compensating differentials theory predicts $\psi_{1}=\psi_{3}=\psi_{5}=0$; the efficiency wage theory predicts $\psi_{1}>0, \psi_{2}, \psi_{3}>0, \psi_{4}, \psi_{5}<0$; while the bargaining theory predicts $\psi_{1}, \psi_{2}>0, \psi_{3}<0, \psi_{4}<0, \psi_{5}>0$. These different predictions about the $\psi$ 's and their relationship to the underlying structural parameters are summarized in table 1.

One problem with (20) is that it includes the unobserved expectations of future variables. We deal with this in the now conventional way of invoking rational expectations and replace expectations by their actual values plus an expectational error. Doing this leads to

$$
e_{i t}=\psi_{0}+\psi_{1} e_{i t+1}+\psi_{2} w_{i t}+\psi_{3} w_{i t+1}+\psi_{4} \bar{u}_{i t}+\psi_{5} \bar{u}_{i t+1}+\varepsilon_{i t+1},
$$

where $\varepsilon_{t+1}$ is a composite expectational error term satisfying $E_{t} \varepsilon_{t+1}=0$. Now substituting the expression (18) for effort we arrive at, after some rearrangement,

$$
\begin{aligned}
y_{i t}= & \gamma \psi_{0}+\psi_{1} y_{i t+1}+\beta \ell_{i t}-\psi_{1} \beta \ell_{i t+1}+\alpha k_{i t}-\psi_{1} \alpha k_{i t+1} \\
& +\gamma \psi_{2} w_{i t}+\gamma \psi_{3} w_{i t+1}+\gamma \psi_{4} \bar{u}_{i t}+\gamma \psi_{5} \bar{u}_{i t+1} \\
& +\gamma \varepsilon_{i t+1}+v_{i t}+\psi_{1} v_{i t+1}+\left(1-\psi_{1}\right) a_{i}+\text { other dummies. }
\end{aligned}
$$

This is the equation that we will estimate.

Table 1

Structural Parameters of the Three Dynamic Models of Worker Effort Determination

\begin{tabular}{lccc}
\hline Coefficient & $\begin{array}{c}\text { Compensating } \\
\text { Differentials } \\
\text { Model }\end{array}$ & Efficiency Wage Model & $\begin{array}{c}\text { Bargaining } \\
\text { Model }\end{array}$ \\
\hline$e_{t+1}$ & 0 & $\delta(1-q) p$ & $\delta$ \\
$w_{t}$ & 1 & $(1-p)(1-\theta)$ & 1 \\
$w_{t+1}$ & 0 & $\delta(1-p)(1-q) \theta$ & $-\delta$ \\
$\bar{u}_{t}$ & -1 & $-(1-p) \varphi$ & $-\mu$ \\
$\bar{u}_{t+1}$ & 0 & $-\delta(1-p)(1-q)(1-\varphi)$ & $\delta \mu(1-q+q \mu)$ \\
\hline
\end{tabular}

NOTE.-Explanation of parameters: $\delta=$ discount factor; $q=$ quit rate; $p=$ probability of shirker not being caught; $\theta=$ probability of being paid current wage for caught shirker; $\varphi=$ probability of receiving alternative utility level this period for caught shirker; and $\mu=$ markup in wage bargaining. 
There are several points that need discussing. First, to eliminate firmspecific effects, we will estimate (22) in first differences. This means that the earliest legitimate instruments will be those of date $(t-2)$. Second, consider the nature of the error term in (22). If $v_{i t}$, the errors in the production function are white noise, the error in (22) will, after first differencing, possibly have an MA(1) structure (depending on the correlation between $\varepsilon_{i t}$ and $\left.v_{i t}\right) .{ }^{5}$ If, instead, $v_{i t}$ has an $\mathrm{AR}(1)$ structure, then the error in $(22)$ will possibly have an $\operatorname{ARMA}(1,1)$ structure. Given that the procedure of estimating in first differences will tend to induce first-order autocorrelation in the equation error, we are careful to test for the presence of second-order residual autocorrelation in our equations and to check whether the first-order residual covariance is close to 0.5 , which is what we would expect if the errors in (22) are white noise.

The identification of (22) also deserves some discussion. What we are estimating are the wage-effort combinations at which effective labor will be available to the firm. An attempt to pay workers a lower wage, for example, would in the compensating differentials model cause workers to quit, in the union model it would cause them to strike, and in the efficiency wage model it would cause them to shirk. So, what we are estimating is really the supply curve of labor to the firm. One worry about identification might be the following. If firms were on their labor demand curves, and if, for example, the technology had a constant elasticity of substitution, then labor productivity would be positively related to the real product wage. We need to ensure that when we estimate (22), we are not estimating this type of relationship. To identify (22) as the supply curve of labor to the firm we need to use as instruments variables that will influence labor demand (and the choice of effort) but that do not directly enter into (22). One obvious instrument is the product wage; as our theories concern the supply side, the wage variable is the consumer wage. But, as available measures of product prices are less than ideal (i.e., not at firm level), we also use profits as an instrument as they will be influenced by the product price and other factors shifting demand for the firm's product.

Finally, another issue is why we use an approach based on direct estimation of the production function. One might also think of estimating factor demands that will, in general, depend on worker effort and then eliminate effort in the way that we did above to derive an estimable Euler equation (Green and Weisskopf [1990] follow a somewhat similar approach when they estimate hours equations based on a "cost-of-job-loss" model). We do not follow this approach for two reasons. First, the real product

${ }^{5}$ One might expect that the composite error term in (22) would be almost certain to have an MA(1) structure because it includes both $v_{i t}$ and $v_{i t+1}$. But the expectational error $\varepsilon_{i t+1}$ is almost certainly strongly correlated with $v_{i t+1}$, making such a conclusion invalid. 
wage will enter factor demands directly, and this will affect the predicted signs on our coefficients, making our tests much less clear-cut and causing more serious problems with identification. One could distinguish between product and consumer wages, but given the lack of good measures of product prices this is unlikely to be very satisfactory. And if there is some kind of bargaining by unions over the level of employment (as, e.g., in the efficient bargaining model of McDonald and Solow [1981]), the alternative utility level will also appear directly in factor demands (see Nickell and Wadhwani [in press] for a fuller discussion of this).

Second, we know that dynamics are very important in factor demands, and if we are estimating Euler equations, it is very important that these dynamics are modeled properly (see Machin, Manning, and Meghir [1991] for one approach using essentially this data set).

For these reasons, we believe that estimating production functions directly offers the best hope of a clear-cut test of the hypotheses in which we are interested, and this is the approach that we take.

\section{The Data}

The data we use are an unbalanced panel of 486 U.K.-quoted companies drawn from the Datastream data bank, over the period 1976-86. The balance of the panel is such that we have 253 firms with 7 years data, 52 with 8,44 with 9,89 with 10 , and 48 with 11 . This is the same data source as used by Wadhwani and Wall (in press) in their study.

Accounts data are clearly attractive in that they give us a panel aspect, although they do have some shortcomings. In particular, we are forced (like Wadhwani and Wall) to model $y_{i t}$ as the log of real sales as we do not have data on value added. The variables $k_{i t}$ and $l_{i t}$ are measured by capital stock and total U.K. employment data, while $w_{i t}$ is the log of the average real wage in the firm. The variable $\bar{w}_{i t}$ is defined as $\left[\left(1-u r_{t}\right) w_{t}^{i}+u r_{t} b_{t}\right]$, where $w_{t}^{i}$ is the log of the industry wage and $u r$ and $b$ are the aggregate unemployment rate and benefit levels, respectively.

The reported models are estimated in first differences to remove fixed effects using instrumental variable methods designed for unbalanced panels, as described by Arellano and Bond (1991). Effectively, this amounts to using an optimal set of instruments to obtain efficient parameter estimates (in the absence of serial correlation). Tests of instrument validity are also presented to ensure the instrument set used is uncorrelated with the residuals of the equation.

\section{Results}

Our main results are presented in table 2. Columns 1 and 2 present estimates of (22), including industry measures of alternative utility both with and without industry dummies. Column 3 presents estimates omitting 
Table 2

Unrestricted Models

\begin{tabular}{|c|c|c|c|c|c|}
\hline & (1) & (2) & (3) & (4) & (5) \\
\hline Constant & $\begin{array}{l}.014 \\
(.016)\end{array}$ & $\begin{array}{c}-.002 \\
(.011)\end{array}$ & $\begin{array}{l}\cdots \\
\cdots\end{array}$ & $\begin{array}{l}.009 \\
(.013)\end{array}$ & $\begin{array}{l}.018 \\
(.015)\end{array}$ \\
\hline$y_{i(t+1)}$ & $\begin{array}{l}.423 \\
(.067)\end{array}$ & $\begin{array}{l}.652 \\
(.050)\end{array}$ & $\begin{array}{l}.663 \\
(.048)\end{array}$ & $\begin{array}{l}.441 \\
(.066)\end{array}$ & $\begin{array}{l}\ldots \\
\ldots\end{array}$ \\
\hline$k_{i t}$ & $\begin{array}{l}.218 \\
(.084)\end{array}$ & $\begin{array}{l}.269 \\
(.080)\end{array}$ & $\begin{array}{l}.233 \\
(.047)\end{array}$ & $\begin{array}{l}.241 \\
(.083)\end{array}$ & $\begin{array}{l}.045 \\
(.056)\end{array}$ \\
\hline$k_{i(t+1)}$ & $\begin{array}{l}-.214 \\
(.084)\end{array}$ & $\begin{array}{r}-.240 \\
(.070)\end{array}$ & $\begin{array}{c}-.122 \\
(.046)\end{array}$ & $\begin{array}{r}-.236 \\
(.079)\end{array}$ & $\begin{array}{l}\ldots \\
\ldots\end{array}$ \\
\hline$\ell_{i t}$ & $\begin{array}{l}.376 \\
(.103)\end{array}$ & $\begin{array}{l}.458 \\
(.096)\end{array}$ & $\begin{array}{l}.373 \\
(.081)\end{array}$ & $\begin{array}{l}.371 \\
(.104)\end{array}$ & $\begin{array}{l}.428 \\
(.069)\end{array}$ \\
\hline$\ell_{i(t+1)}$ & $\begin{array}{l}-.169 \\
(.099)\end{array}$ & $\begin{array}{l}-.438 \\
(.084)\end{array}$ & $\begin{array}{l}-.163 \\
(.066)\end{array}$ & $\begin{array}{l}-.163 \\
(.097)\end{array}$ & $\begin{array}{l}\cdots \\
\cdots\end{array}$ \\
\hline$w_{i t}$ & $\begin{array}{l}.737 \\
(.150)\end{array}$ & $\begin{array}{l}.716 \\
(.135)\end{array}$ & $\begin{array}{l}.544 \\
(.109)\end{array}$ & $\begin{array}{l}.745 \\
(.151)\end{array}$ & $\begin{array}{l}.647 \\
(.121)\end{array}$ \\
\hline$w_{i(t+1)}$ & $\begin{array}{l}-.345 \\
(.155)\end{array}$ & $\begin{array}{l}-.438 \\
(.144)\end{array}$ & $\begin{array}{l}-.289 \\
(.136)\end{array}$ & $\begin{array}{r}-.384 \\
(.153)\end{array}$ & $\begin{array}{l}\ldots \\
\ldots\end{array}$ \\
\hline $\bar{u}_{i t}$ & $\begin{array}{l}.185 \\
(.265)\end{array}$ & $\begin{array}{l}.221 \\
(.162)\end{array}$ & $\begin{array}{l}-.091 \\
(.116)\end{array}$ & $\begin{array}{l}\ldots \\
\ldots\end{array}$ & $\begin{array}{l}.038 \\
(.188)\end{array}$ \\
\hline $\bar{u}_{i(t+1)}$ & $\begin{array}{l}-.401 \\
(.307)\end{array}$ & $\begin{array}{r}-.380 \\
(.240)\end{array}$ & $\begin{array}{l}.085 \\
(.165)\end{array}$ & $\begin{array}{l}\cdots \\
\cdots\end{array}$ & $\begin{array}{l}\cdots \\
\cdots\end{array}$ \\
\hline Time dummies & $108.2[8]$ & $83.8[8]$ & $*$ & $109.5[8]$ & $159.0[8]$ \\
\hline Industry dummies & $67.7[13]$ & $*$ & $*$ & 65.8 [13] & $121.7[13$ \\
\hline $\begin{array}{l}\text { Sargan } \\
\text { Second-order serial } \\
\text { correlation, }\end{array}$ & $56.7[53]$ & $76.6[66]$ & $116.4[74]$ & $57.8[55]$ & $60.1[58$ \\
\hline $\begin{array}{l}N(0,1) \\
\text { First-order residual }\end{array}$ & .453 & .390 & -.838 & .615 & -1.614 \\
\hline covariance & -.520 & -.648 & -.641 & -.527 & -.200 \\
\hline
\end{tabular}

NOTE. - Number of firms $=486 . N=2,543$. The dependent variable is $y_{i t}$. Asymptotic standard errors are in parentheses. All models are estimated in the first differences using Arellano and Bond's (1991) twostep instrumental variable estimator. All variables are instrumented using lags dated $(t-2)$ for each period on all variables (eight instruments per variable from 1979-86), $(t-3)$ each period on $k$ and $\ell$, and all models include $(t-2)$ dated profits as outside instruments. A Sargan $\chi^{2}$ test of the implied overidentifying restrictions is also reported (degrees of freedom in brackets). A test for second-order serial correlation is presented: it is a $N(0,1)$ statistic (see Arellano and Bond 1991). Wald tests of the significance of including industry or time dummies are presented where they were included (degrees of freedom in brackets).

* Estimates omitted from model.

both industry and time dummies, while column 4 includes both and omits the alternative utility level.

In all cases the results are very similar. First, there is no evidence of second-order residual autocorrelation in any of the equations, and the first-order residual covariance is always close to -0.5 , indicating that the hypothesis that the errors in (22) are white noise is acceptable. Second, the coefficients on $y, k$, and $\ell$ are all of the right sign and statistically significant. ${ }^{6}$ Overall, the estimated coefficients on future output and the

${ }^{6}$ The estimated elasticity of output with respect to the capital stock is on the small side, but this is not too surprising given the problems in computing an adequate measure of the capital stock from company accounts data. 
factor inputs suggest that the approach we have adopted is a broadly sensible one.

Now consider which of the three theories we have considered is more supported by the data. First, consider the compensating differentials model. This predicts that all the future variables should be insignificant. It is not hard to see that these restrictions are rejected. More formally, column 5 presents estimates of a static model. And Wald tests for the exclusion of the future terms from columns $1-4$ range from $\chi^{2}(5)=47.3$ for column 1 to $\chi^{2}(5)=325.9$ for column 3 .

Second consider the efficiency wage model. This predicts that the coefficients on current and future wages should both be positive while those on the current and future alternative utility level should both be negative. From the inspection of the coefficient on $w_{i t+1}$ in all the equations it can be seen that this prediction finds little support here.

The predictions of the collective bargaining model do, however, get more support. The coefficients on current and future wages are exactly as predicted, and while the coefficients on the alternative wage are the opposite to those predicted, these coefficients are insignificant. This is not too surprising given that a substantial part of the alternative wage may be captured by the time dummies. Indeed, when we omit the time dummies in column 3 , the signs on the alternative wage terms are consistent with the bargaining model, although they are not large enough in absolute terms. However, the $\chi^{2}$ test of the overidentifying restrictions implied by the instrument set fails in column 3. Furthermore, it should be noted that the time dummies are always jointly significant even when the alternative utility level is included.

But the conclusion that the bargaining model best explains the data may be too premature. We split the sample into industries with high and low unionization using, after some experimentation, a dividing line of 50\% union density in 1979. The data for industry union density are taken from Price and Bain (1983). The results are presented in table 3.

The most striking difference is that now the sign on the future wage is significantly positive in the low union density sample while it remains significantly negative in the high union density sample. This is consistent with the plausible view that the efficiency wage model is more relevant for firms in which unions are weak and that the bargaining model is more relevant for models in which unions are strong. The parameter estimates in table 3 provide some other evidence for this view. The coefficients on future output and the future wage are higher in the high union density sample, which is what our theory predicts (look at table 1). But, as before, the coefficients on the alternative utility level do not conform to either theory (although they are insignificant).

One direction in which to go from the equations estimated in table 2 is to derive estimates of the underlying structural parameters. This we are 
Table 3

Disaggregation by Industry Unionization

\begin{tabular}{lcc}
\hline & $\begin{array}{c}\text { High Union } \\
\text { Density }\end{array}$ & $\begin{array}{c}\text { Low Union } \\
\text { Density }\end{array}$ \\
\hline Constant & .043 & -.023 \\
$y_{i(t+1)}$ & $(.022)$ & $(.024)$ \\
$k_{i t}$ & .408 & -.023 \\
& $(.105)$ & $(.143)$ \\
$k_{i(t+1)}$ & .136 & .121 \\
$\ell_{i t}$ & $(.110)$ & $(.112)$ \\
& -.181 & .034 \\
$\ell_{i(t+1)}$ & $(.093)$ & $(.123)$ \\
$w_{i t}$ & .371 & .613 \\
& $(.138)$ & $(.154)$ \\
$w_{i(t+1)}$ & -.148 & .110 \\
$\bar{u}_{i t}$ & $(.109)$ & $(.141)$ \\
$\bar{u}_{i(t+1)}$ & .650 & .672 \\
& $(.209)$ & $(.208)$ \\
Time dummies & -.558 & .634 \\
Industry dummies & $(.120)$ & $(.317)$ \\
Sargan & -.055 & -.073 \\
Second-order serial correlation & $(.409)$ & $(.269)$ \\
First-order residual covariance & -.386 & -.037 \\
No. of firms & $(.522)$ & $(.325)$ \\
Sample size & $49.6[8]$ & $25.6[8]$ \\
\hline & $27.9[9]$ & $.8[3]$ \\
Sour & .589 & $54.5[53]$ \\
& -.481 & -1.315 \\
& 390 & -.530 \\
& 2,002 & 96 \\
& & 541 \\
\hline
\end{tabular}

SOURCE.-See Price and Bain (1983).

NOTE.-As for table 1. High (low) union density refers to industries with unionization above (below) $50 \%$ in 1979 .

reluctant to do because our sample split is imperfect with the result that, for example, our high (low) union density sample almost certainly contains some firms for which the efficiency wage (bargaining) model is relevant, and this would bias our estimates of the underlying structural parameters.

Our conclusions are that we do have some evidence that, in firms where unions are not very powerful, the efficiency wage model does seem relevant while a bargaining model seems better for firms with powerful unions. We are cautious about our conclusions because it is conceivable that other models could explain these results. For example, a model of rent sharing, which is another form of a bargaining model, would probably imply something very similar, as would a model of intertemporal substitution. ${ }^{7} \mathrm{How}^{-}$ ever, the fact that our results depend on the sample split we have used makes us believe that our conclusions are not entirely unjustified.

7 Another possibility that might be suggested to explain our results is the compensating differentials model but with a production function with an AR(1) model providing the dynamics. However, if the AR process were stationary, this would 


\section{Conclusion}

This article has extended the recent literature on the empirical implications of alternative models of the labor market. We have pointed out that, although these alternative models are often predicted to have the same long-run comparative statics, one can develop different predictions from these theories if one estimates empirical models derived from simple dynamic versions of the theories. The evidence that we have provided is consistent with the shirking version of the efficiency wage model for firms where unions are not very important (a minority of firms in our sample), but the bargaining model seems better for firms in highly unionized industries. We are not surprised by this result. Collective bargaining is very important in the large British firms in our sample, and it is not particularly credible to believe that only the threat of shirking keeps wages high.

\section{References}

$\rightarrow$ Akerlof, G. A. "Labor Contracts as Partial Gift Exchange." Quarterly Journal of Economics 97 (1982): 543-69.

$\rightarrow$ Akerlof, G. A., and Katz, L. "Workers' Trust Funds and the Logic of Wage Profiles." Quarterly Journal of Economics 104 (1989): 525-36.

$\rightarrow$ Arellano, M., and Bond, S. "Some Tests of Specification for Panel Data: Monte Carlo Evidence and an Application to Employment Equations." Review of Economic Studies 58 (1991): 277-98.

Gibbons, R., and Katz, L. "Unmeasured Ability and Inter-industry Wage Differences." Working paper. Cambridge, Mass.: National Bureau of Economic Research, October 1989.

$\rightarrow$ Green, F., and Weisskopf, T. E. "The Worker Discipline Effect: A Disaggregative Analysis." Review of Economics and Statistics 72 (1990): 24149.

$\rightarrow$ Krueger, A., and Summers, L. "Efficiency Wages and the Inter-industry Wage Structure." Econometrica 56 (1988): 259-93.

$\rightarrow$ McDonald, I., and Solow, R. "Wage Bargaining and Employment." American Economic Review 71 (1981): 896-908.

Machin, S.; Manning, A.; and Meghir, C. "Dynamic Models of Employment Based on Firm Level Panel Data." Working paper. London: London School of Economics, September 1991.

Macleod, W. B., and Malcomson, J. M. "Implicit Contracts, Incentive Compatibility and Involuntary Unemployment." Econometrica 57 (1989): 447-80.

$\rightarrow$ Malcomson, J. M. "Work Incentives, Hierarchy and Internal Labor Markets." Journal of Political Economy 92 (1984): 486-507.

imply that a regression of current on lagged output would have a coefficient less than one. As we regress current on future output, we would expect a coefficient on future output larger than one if this explanation for our results were correct. We do not find this. 
Murphy, K. M., and Topel, R. "Unemployment, Risk and Earnings." In Unemployment and the Structure of Labor Markets, edited by K. Lang and J. Leonard. London: Basil Blackwell, 1987.

Nickell, S., and Wadhwani, S. "Employment Determination in British Industry: Investigations Using Micro-data." Review of Economic Studies (in press).

Nickell, S.; Wadhwani, S.; and Wall, M. "Unions and Productivity Growth in Britain, 1974-86: Evidence from U.K. Company Accounts Data." Discussion Paper no. 353. London: London School of Economics, Centre for Labour Economics, August 1989.

Price, R., and Bain, G. S. "Union Growth in Britain: Retrospect and Prospect." British Journal of Industrial Relations 21 (1983): 46-68.

$\rightarrow$ Shapiro, C., and Stiglitz, J. E. "Equilibrium Unemployment as a Worker Discipline Device." American Economic Review 74 (1984): 433-44.

$\rightarrow$ Stewart, M. "Union Wage Differentials in the Face of Changes in the Economic and Legal Environment." Economica 58 (1991): 155-72.

Wadhwani, S., and Wall, M. "A Direct Test of the Efficiency Wage Model Using U.K. Micro-data." Ox ford Economic Papers (in press).

Weisskopf, T.; Bowles, S.; and Gordon, D.; "Hearts and Minds: A Social Model of US Productivity Growth." Brookings Papers on Economic Activity, no. 2 (1983), pp. 381-450. 